\title{
A Responsabilidade Social Corporativa modera a relação entre o traço maquiavélico e o gerenciamento de resultados?
}

\author{
Márcia Figueredo D'Souza
}

https://orcid.org/0000-0002-3196-5396 | E-mail:marciafdsouza@yahoo.com.br

\section{Resumo}

Objetivo: Analisar a relação entre o traço de personalidade maquiavélico e a Responsabilidade Social Corporativa (RSC) e o gerenciamento de resultado, à luz da teoria do Alto Escalão.

Método: Estudo empírico teórico, sendo o survey o procedimento de coleta de dados, aplicado a 208 profissionais de negócios. A estatística descritiva, teste de hipóteses e regressão foram aplicados.

Resultados: Os profissionais que se preocupam em observar as políticas que remetem à responsabilidade legal, não concordam com a prática de gerenciamento de resultados, no entanto, aqueles que focalizam a responsabilidade econômica, apresentaram disposição para o gerenciamento. Quanto à influência maquiavélica, aqueles mais dotados desses traços apresentam menor disposição para a responsabilidade corporativa legal e ética e maior aceitação para o gerenciamento de resultados. Em adição, contrariamente às expectativas, a moderação da RSC não reduziu a relação positiva entre o Maquiavelismo e o gerenciamento de resultados.

Contribuições: Os resultados permitem ampliar a discussão da pesquisa interdisciplinar em contabilidade comportamental e fornece insights sobre como o Maquiavelismo pode influenciar as decisões empresariais e a conduta social. Implicações econômicas e sociais dos achados interessam aos profissionais da contabilidade, investidores e auditores para compreensão sobre o impacto ou prejuízo causado pelo gerenciamento de resultados na informação contábil.

Palavras-chave: Responsabilidade Social Corporativa; Gerenciamento de Resultados; Maquiavelismo. 


\section{Introdução}

Escândalos contábeis como os famosos casos Petrobras, General Motors, Toshiba, Lehman Brothers, Shell, WorldCom e Enron, incitam a discussão sobre a importância da RSC no contexto empresarial. A falta de transparência das informações contábeis e manipulações de resultados realizadas pelos gestores foram atribuídas, à época, à decadência da moralidade nos negócios, traduzida pela falta de RSC (Chih, Shen,\&Kang, 2008).

A RSC são as ações e políticas específicas realizadas no contexto organizacional, que levam em consideração o tripé da performance econômica, social e ambiental e as expectativas dos stakeholders. As empresas nela engajadas estão propensas a melhorar a reputação, fidelização de clientes e avaliações de produtos (Aguinis, 2011), dado que as políticas internas influenciamas atitudes e os comportamentos dos gestores e colaboradores (Leal, 2013). A RSC abrange aspectos econômicos, legais, éticos e de discricionariedade (Carrol, 1979).

Essa temática tem sido objeto de estudos que investigam performance financeira corporativa (Leal, 2013; Callan \& Thomas, 2009; Orlitzky, Schmidt, \&Rynes, 2003). Há estudos que consideraram importante discutir se a RSC inibe o gerenciamento de resultados, pois o desempenho individual e empresarial pode ser mascarado quando os gestores têm disposição para manipular os ganhos para refletir um desempenho superior ao verdadeiramente alcançado. Shafer e Lucianetti (2018) e Shafer (2015) enfatizam que ética corporativa e responsabilidade social são indicadores de redução de manipulação de lucros. Chih et al. (2008) argumentam que a RSC aumenta a transparência da informação contábil e reduz o número de oportunidades para gerenciar ganhos.

O gerenciamento de resultados é observado sob duas perspectivas: informacional e oportunística. A informacional foca na escolha de políticas contábeis, especialmente na mudança de critérios contábeis pela flexibilidade das normas e dos padrões contábeis. É difícil perceber se tais mudanças representam manipulação ou apenas uma escolha contábil discricional. A oportunística tem o propósito de utilizar a informação contábil para enganar os principais interessados quanto aos resultados operacionais. As informações são distorcidas de forma intencional, ocasionando a fraude de resultados (Mohanram, 2003).

Estudos no âmbito comportamental sugerem que a prática de manipular resultados é motivada pela personalidade dos indivíduos (Silva, 2019; D’Souza, Lima, Jones, \& Carre, 2019; Góis, 2017;D’Souza, 2016; D’Souza \& Lima, 2015) porque, como enuncia a teoria do Alto Escalão (Hambrick, 2007; Hambrick \& Mason, 1984), as interpretações e escolhas de executivos estão relacionadas às características pessoais, aos valores e à personalidade.

Indivíduos com traços de personalidades sombrias, não patológicos, tal como o Maquiavelismo, manifestam no meio empresarial baixos padrões de ética e moral, estratégia com foco em ganho de longo prazo e ausência de princípios. O Maquiavelismo "é um traço de personalidade marcado por uma atitude calculista em relação a relacionamentos humanos e uma crença de que os fins justificam os meios, embora desumana". Os indivíduos maquiavélicos veem os outros mais ou menos como objetos a serem manipulados na busca de objetivos, mesmo que para isso cometam fraudes deliberadas (VanderBos, 2010, p. 574). São propensos à manipulação de resultados para maximização de ganhos pessoais e empresariais (D’Souza, 2016).

No tocante à orientação maquiavélica sobre a RSC, Burton e Hegarty (1999) observaram que os gestores dão maior importância às responsabilidades econômicas e pouca atenção à responsabilidade ética e legal. Se por um lado os indivíduos maquiavélicos se preocupam com a reputação, por outro, a insensibilidade, a manipulação e a desonestidade são características marcantes desse traço de personalidade. 
Nesse contexto, este estudo pretende elucidar o seguinte problema de pesquisa: Qual a relação entre o traço de personalidade maquiavélico e a responsabilidade social corporativa e o gerenciamento de resultados? Pretende-se, portanto, analisar a relação entre o traço de personalidade maquiavélico e a responsabilidade social corporativa e o gerenciamento de resultados. Para tanto, foram pesquisados 208 profissionais de negócios e os resultados dessa pesquisa apontam que quanto maior a propensão para a responsabilidade legal, menor a disposição para o gerenciamento de resultados. Efeito contrário foi evidenciado quando se analisou a responsabilidade econômica. Sobre a influência maquiavélica, quanto mais forte o traço, menor a motivação dos indivíduos para a responsabilidade corporativa legal e ética, e maior aceitação para práticas de gerenciamento de resultados. Em adição, contrária às expectativas, a moderação da RSC não reduziu a relação entre o Maquiavelismo e o gerenciamento de resultados.

Os resultados evidenciam a relevância teórica e prática deste estudo. Teórica por ampliar o debate do estudo interdisciplinar que discute temáticas da área de negócios e da área psicológica, ainda pouco explorado nacionalmente na área de negócios, além de trazer a fundamentação teórica sobre a abordagem da teoria do Alto Escalão, que guarda forte relação com as temáticas RSC, gerenciamento de resultados e traços de personalidade maquiavélicos. Ainda nesse aspecto, cabe considerar a contribuição metodológica de um estudo empírico com profissionais de negócios que atuam ou já atuaram na área de gestão e possuem habilidade para interpretar o processo decisório em organizações, o que permite a análise crítica dos resultados obtidos.

Busca-se, além da análise separada entre as temáticas, preencher uma lacuna teórica sobre o conhecimento da moderação da RSC na relação entre o Maquiavelismo e o gerenciamento de resultados, haja vista estudos anteriores terem se debruçado a discutir de forma separada a relação em par das temáticas Maquiavelismo e RSC (Shafer \& Lucianetti, 2018; Burton \& Hegarty, 1999) e Maquiavelismo e gerenciamento de resultados (Hartmann \& Maas, 2010; Murphy, 2012; Byngton \& Johnson, 2011), ou a análise de outros traços sombrios de personalidade: narcisismo, RSC e gerenciamento (Lin, Sui, Ma, Wang, \&Zeng, 2018; Petrenko, Aime, Ridge, \& Hill, 2016; Tang, Mack, \& Chen, 2018), Dark Tetrad (Narcisismo, Maquiavelismo, Psicopatia e Sadismo), mecanismos de governança corporativa e gerenciamento de resultados (Silva, 2019); e o Dark Tetrad, reputação corporativa e a qualidade da informação contábil (Góis, 2017).

A contribuição prática se dá pelas implicações econômicas e sociais dos achados que interessam aos profissionais da contabilidade, tais como:auditores, reguladores e também os responsáveis pela governança corporativa e gerentes de negócios que formulam as políticas internas sobre o impacto ou o prejuízo causado pelo gerenciamento de resultado, que remete a manipulações operacionais que não violam as leis, e manipulações contábeis que violam as leis(Merchant, 1989). Desenvolve ainda uma compreensão de como o Maquiavelismo pode influenciar na conduta social dos líderes, dentro e fora das empresas, sobretudo no reporte sobre a performance social e financeira das empresas para a sociedade. Como as organizações são gerenciadas e lideradas por indivíduos que possuem características diversas, os resultados oportunizam a discussão de que as decisões empresariais refletem os valores e interesses desses gestores.

Este artigo está dividido em cinco seções. A primeira é esta, a introdução, que apresenta a problemática, a justificativa, o objetivo e um resumo dos principais resultados do estudo. A segunda contém o referencial teórico explorado e a construção das hipóteses, que apresenta a discussão sobre a responsabilidade social corporativa, o gerenciamento de resultados, o Maquiavelismo e os estudos anteriores. Na terceira têm-se a metodologia e informações sobre o objeto de estudo; na quarta a análise de resultados; e na quinta, última seção, as conclusões. 


\section{Responsabilidade Social Corporativa}

O tema RSC tem ganhado importância nas pesquisas acadêmicas. Um dos primeiros artigos a jogar luz sobre o assunto foi o de Carroll (1979) - um modelo conceitual sobre os aspectos essenciais da performance social corporativa. As diversas pesquisas relacionadas trouxeram diferentes conceitos e definições de RSC. Maignan, Ferrell e Hult (1999) destacaram a importância dos stakeholders e do desempenho social das empresas para a RSC e a definiram como "o quanto as empresas satisfazem as responsabilidades econômicas, legais, éticas e discricionárias identificadas pelos seus diversos stakeholders" (p. 457). Em complemento, Aguinis (2011), definiu RSC como "ações e políticas específicas realizadas no contexto organizacional, que levam em consideração as expectativas dos stakeholders e o tripé da performance econômica, social e ambiental". Em comum, percebe-se que tais definições de RSC sempre apresentam um conceito abrangente, que envolve ações econômicas, legais e sociais.

Essa amplitude dos conceitos nos remete ao modelo conceitual de Carroll (1979), que ressaltou que a RSC deve abranger aspectos econômicos, legais, éticos e de discricionariedade. O aspecto econômico descrito pelo autor informa que as empresas têm como objetivo principal serem agentes econômicos produtores de bens e serviços demandados pela sociedade e vendidos a ela com lucro. Já o aspecto legal, ainda segundo o autor, indica que a sociedade espera que as empresas realizem suas atividades seguindo os requerimentos legais. O aspecto ético se relaciona com os aspectos legais, porém Carroll (1979) o descreve como um nível além do cumprimento da lei, de forma que as empresas devam buscar a ética em suas ações. Por fim, há o aspecto discricionário das empresas, ou seja, ações adicionais, voluntárias, não requeridas por lei, mas que visam ao bem social, tais como as contribuições filantrópicas.

Considerando que as empresas, em geral, têm o objetivo de maximizar seus lucros e, consequentemente, a riqueza dos acionistas, não se pode dissociar a RSC desse objetivo. Drucker (1984) destacou que a RSC seria uma oportunidade de negócios vista pelas empresas. Mais do que um comportamento genuinamente social e filantrópico, como algumas definições levam a entender, a RSC passou a ser perseguida por satisfazer o desejo dos acionistas. Hong e Andersen (2011) denominaram tal fenômeno de "filantropia estratégica" - a RSC, mais do que uma atitude benevolente das empresas, seria ações voltadas à geração de resultados positivos para os acionistas.

As ações de RSC seriam destinadas a buscar melhores resultados. Não por acaso, boa parte da literatura acadêmica sobre RSC procurou relacioná-la com a performance financeira das empresas, haja vista que um maior investimento em RSC levaria a um melhor desempenho. Estudos como o de Callan e Thomas (2009) e Orlitzky et al. (2003) investigaram a relação entre RSC e performance financeira no mercado americano e identificaram relação positiva entre os constructos. Leal (2013), ao realizar um estudo sobre RSC, aspectos psicológicos e desempenho individual, com funcionários de empresas portuguesas, percebeu que a RSC exerce um efeito indireto sobre o desempenho individual.

Nesse contexto, a teoria do Alto Escalão (Hambrick \& Mason, 1984; Hambrick, 2007) fundamenta o comportamento do gestor sobre as escolhas e os interesses resultantes de valores, características e personalidade dos indivíduos que influenciam as decisões econômicas e sociais das corporações. Dessa forma, o presente estudo apoia-se nos princípios da teoria do Alto Escalão ao avaliar as características pessoais dos gestores e a sua relação com a RSC, por meio de potenciais ações de gerenciamento de resultados. 


\section{Gerenciamento de Resultados}

Segundo Merchant (1989), o gerenciamento de resultados pode ser definido como qualquer ação, por parte da gestão, que afeta o resultado declarado, não fornece vantagem econômica verdadeira para a organização e pode, em longo prazo, ser bastante prejudicial para os diversos usuários da informação contábil. O procedimento tem por propósito enganar partes interessadas quanto à situação econômica e ao desempenho da empresa, e influenciar os resultados contratuais que dependem dos números contábeis reportados. Para tanto, o gestor exercita a discricionaridade sobre os números contábeis, com ou sem restrição. Os critérios adotados refletem na maximização do valor da empresa ou em uma postura oportunística (Healy\&Wahlen, 1999).

Três formas de gerenciamento de resultados são investigadas na literatura: gerenciamento por accruals, gerenciamento real e mudança de classificação. O gerenciamento por accruals ocorre quando, por meio de acumulações discricionárias, os gestores "emprestam" os lucros de períodos futuros para aumentar o resultado do período corrente, ou, inversamente, empurram os ganhos do período atual para o futuro. Por conseguinte, os custos incorridos para aumentar ganhos correntes, em adição ao custo de detecção, são deduzidos dos ganhos futuros. Os resultados de períodos futuros são reduzidos, mecanicamente, como resultados do lucro líquido que é acelerado para o período atual (Albernathy, Beyer, \&Rapley, 2014).

O gerenciamento real de resultados ocorre quando os gerentes se desviam de ótimas decisões de negócios para reais atividades de gerenciamento como, por exemplo, superprodução para reduzir o custo dos produtos vendidos (CPV), mediante corte de despesas discricionárias, como em pesquisa e desenvolvimento, para atender a metas de lucros (Albernathy et al., 2014)

Outra prática de gerenciamento é a mudança de classificação das contas patrimoniais e de resultados. McVay (2006) evidenciou que, oportunisticamente, os gestores deslocam despesas essenciais, como custo de mercadorias vendidas e gastos com vendas, gerais e administrativos, para itens especiais (receitas ou despesas das quais não se espera breve repetição, como, por exemplo, despesas extraordinárias, encargos de reestruturações e resultados de operações descontinuadas), com enfoque especial na análise dos números da empresa pelos investidores. Esse movimento vertical de gastos não altera o resultado final (lucro ou prejuízo), mas ressalta um exagero dos ganhos essenciais/operacionais, e favorece, de forma figurativa, o alcance da previsão dos ganhos de benchmark projetados pelos analistas.

Nesse contexto, Merchant (1989) desenvolveu um instrumento de pesquisa com cenários que remetem ao gerenciamento de resultado categorizado por manipulações contábeis que violam os princípios contábeis e manipulações operacionais, caracterizadas pela modificação de ganhos por meio de decisões que não envolvem violações aos regulamentos contábeis, tais como atrasar intencionalmente o registro das despesas para reparos e manutenção, com o intuito de reduzir as despesas do ano corrente, ou a execução de promoções de vendas perto do final do ano para inflar as vendas e receitas reportadas. Nesse particular, cabe exemplificar alguns dos cenários propostos, na Tabela 1: 
Tabela 1

\section{Cenários de gerenciamento de resultados}

\section{Gerenciamento Operacional}

Cenário 1: Em setembro de 2018, o Gerente Geral de uma grande divisão de uma empresa multinacional, percebeu que precisaria de um forte desempenho no quarto trimestre para atingir suas metas orçamentárias. Ele decidiu implementar um programa de vendas que ofereceria condições de pagamento flexível, com o propósito de antecipar algumas vendas que normalmente ocorreriam no próximo ano, para o ano atual. Clientes aceitariam a entrega no quarto trimestre e teriam uma carência de 120 dias para o pagamento da fatura.

AÇÃo: O Gerente Geral da empresa implementou o programa de vendas e, como resultado, a divisão conseguiu cumprir suas metas orçamentárias.

\section{Cenário 2:}

O Gerente Geral de uma pequena indústria tem vivenciado dificuldades financeiras e não alcançaria as metas orçamentárias anuais. Então, ele ordenou que os funcionários adiassem despesas discricionárias (por exemplo, manutenção, publicidade e contratação) para o próximo período contábil.

AÇÃO: O plano do Gerente Geral foi implementado e, como resultado, a empresa conseguiu cumprir suas metas orçamentárias.

\section{Gerenciamento Contábil}

Cenário 3: O Gerente Geral estava se esforçando para cumprir suas previsões de lucros durante o final de 2018. Ele decidiu chamar um sócio de uma empresa parceira de consultoria que estava fazendo um trabalho para a divisão e o pediu para registrar a fatura da prestação de serviço em 2019, embora o honorário da consultoria já tivesse sido incorrido em 2018. O parceiro da consultoria concordou.

Ação: O Gerente Geral não registrou as despesas de honorário com a consultoria no ano corrente e, assim, a divisão cumpriu suas previsões de lucros para 2018.

Cenário 4: O Gerente Geral de uma grande divisão de uma empresa de varejo percebeu perto do final de 2018 que sua divisão excederia significativamente suas metas de lucro orçadas para o ano. Como resultado, ele ordenou que seu Controller desenvolvesse uma lógica para aumentar a provisão de obsolescência de estoques. Assumindo uma visão excessivamente pessimista das perspectivas futuras do mercado, o controlador foi capaz de identificar uma quantidade significativa de produtos acabados a serem totalmente provisionados ou baixados numa perspectiva de venda por valor inferior ao custo desses estoques; mesmo tendo confiança de que o estoque em questão ainda seria vendido no exercício posterior, por valor próximo ao preço de mercado.

Ação: O Gerente Geral implementou sua estratégia de reconhecer o excesso de provisão de estoque. A divisão ainda observou que nas metas de lucro de 2018 tinham algumas provisões de estoques em excesso que poderiam ser usados para aumentar os lucros reportados no futuro.

Fonte: adaptado de Shafer (2015) e Merchant (1989)

Bruns e Merchant (1990) utilizaram o instrumento e aplicaram a pesquisa aos649 gerentes dos EUA e perceberam que as manipulações operacionais eram percebidas de forma mais favorável do que as manipulações contábeis. Em seguida, Merchant e Rockness (1994) aplicaram a pesquisa a gerentes gerais e de pessoal, controladores de unidades operacionais e auditores internos norte-americanos e identificaram que os participantes julgaram as manipulações contábeis mais duramente do que manipulações operacionais.

Nessa mesma perspectiva, Shafer (2015) utilizou os quatro cenários de gerenciamento de resultado do instrumento de Merchant (1989) para investigar a percepção de contadores de Hong Kong sobre a responsabilidade social e ética corporativa e a decisão pelo gerenciamento de resultados. Os achados apontaram a importância da ética e da responsabilidade social sobre as intenções comportamentais dos contadores e sugerem que estes profissionais racionalizam as decisões de gerenciamento alicerçados na ética e na responsabilidade corporativa. Nessa mesma perspectiva, Chih et al. (2008) constataram que as empresas com maior compromisso social reduziram algumas práticas de gerenciamento de resultados.

Assim, com base na revisão de literatura apresentada sobre RSC e gerenciamento de resultados, elenca-se a seguinte hipótese de pesquisa:

- H1: Quanto maior a Responsabilidade Social Corporativa, menor a propensão ao gerenciamento de resultados. 


\section{Maquiavelismo}

Christie e Geis (1970) caracterizaram como indivíduos maquiavélicos aqueles dotados de tática, visão humana e moralidade, além de destreza, manipulação, estratégia, atitudes cínicas e sem princípios, que manipulam outros de acordo com o seu ponto de vista e os seus próprios interesses. O conceito do Maquiavelismo foi denominado com base na filosofia de Niccolò Machiavelli, um conselheiro político da família Médici, que estava no poder no século XVI, em Florença, na Itália. A essência dos conselhos de Maquiavel era a de que "Os fins justificam os meios". Jones (2016) ressalta que a filosofia de Maquiavel e as tendências disposicionais com as quais se alinha facilitam os métodos antissociais dos indivíduos dotados desses traços ao alcance de metas, associadas à ganância e ao egoísmo.

Os indivíduos maquiavélicos têm propensão à manipulação em longo e curto prazo, à renúncia de benefícios de curto prazo para o alcance de benefícios de longo prazo e dão maior atenção à reputação (Jones \& Paulhus, 2009). Jones e Paulhus (2011), após realizarem uma revisão dos escritos de Maquiavel e do estrategista militar Sun Tzu, evidenciaram características que remetem à liderança manipuladora, à preparação, ao planejamento, à premeditação, à conveniência, à racionalidade, ao cinismo, à lógica, ao oportunismo, ao cultivo à reputação e à tendência à tomada de decisão dissociada de preconceitos e simpatias pessoais dos indivíduos maquiavélicos.

Jones (2016) ressalta que os indivíduos maquiavélicos podem ser úteis, em algumas circunstâncias, pela habilidade diferenciada de realizar trabalhos que lhes interessem pessoalmente, no entanto, são abertos ao comportamento antiético. Portanto, não se pode esperar fidelidade do indivíduo maquiavélico por ser um trade-off arriscado.

D’Souza (2016) apresenta as principais características evidenciadas em estudos sobre o Maquiavelismo e que se refletem no meio empresarial, conforme Tabela 2.

Tabela 2

Principais características do Maquiavelismo

\begin{tabular}{ll}
\hline & Características Gerais \\
\hline Amoralidade & Flexibilidade \\
\hline Ausência de princípios & Insensibilidade \\
\hline Ausência de afabilidade & Manipulação interpessoal \\
\hline Baixos padrões de ética e moral & Mentira/Enganação \\
\hline Cálculo estratégico & Oportunismo \\
\hline Capacidade de fazer aliados & Orientação para o futuro - longo prazo \\
\hline Capacidade de influenciar & Estratégia \\
\hline Cinismo & Reputação \\
\hline Desonestidade & Tática \\
\hline & Principais Achados Empíricos no Ambiente Empresarial \\
\hline Estilo racional de tomar decisões & Fraude financeira \\
\hline Estratégia de gestão & Manipulação de rubricas orçamentárias \\
\hline Gerenciamento de resultados & Tática de gestão \\
\hline Foco no poder pessoal & Tomada de decisões antiéticas \\
\hline
\end{tabular}

Fonte: Tabela 14. D’Souza (2016). Manobras financeiras e o Dark Triad: o lado sombrio da gestão.

A próxima seção apresenta os resultados de estudos anteriores organizados de acordo com a elaboração das próximas hipóteses de pesquisa. 


\section{Estudos Anteriores}

\subsection{Maquiavelismo e Responsabilidade Social Corporativa}

Traços de personalidade sombrios têm sido objeto de estudo para análise da responsabilidade social corporativa. Burton e Hegarty (1999) desenvolveram um estudo com 219 estudantes americanos de graduação de negócios para examinar, entre outras variáveis, o efeito da orientação maquiavélica em relação à responsabilidade social corporativa. Os autores perceberam que os respondentes com maior nível de Maquiavelismo demonstraram maior importância com as responsabilidades econômicas. No entanto, os níveis de responsabilidade social diminuíram, na medida em que aumentou o nível de Maquiavelismo, sobretudo, pela pouca importância dos respondentes à responsabilidade legal e ética. Shafer e Lucianetti (2018) constataram que quanto mais forte o traço maquiavélico, menor a disposição para a RSC e para a orientação às partes relacionadas. Esta, por sua vez, mostrou-se positivamente correlacionada à RSC.

Lin et al. (2018) examinaram como os traços psicológicos pessoais afetam as práticas da responsabilidade social corporativa dos principais gerentes de organizações chinesas, que participam de megaprojetos. Elegeram o Narcisismo, um traço de personalidade também sombrio, com um foco particular, e perceberam que quanto maior o grau de Narcisismo dos CEOs, menor o grau de responsabilidade social no megaprojeto.

Por outro lado, Petrenko et al. (2016) desenvolveram um estudo com uma amostra de CEOs da Fortune 500 para verificar o efeito das práticas de responsabilidade social corporativa no narcisismo em CEOs. Os autores confirmaram que o desejo de atenção e reforço à imagem do CEO de personalidade sombria têm efeitos positivos nos níveis e perfis da responsabilidade social corporativa. Tang et al. (2015) também estudaram a influência do narcisismo e a responsabilidade social corporativa com 1500 empresas da S\&P, no período de 2003 a 2010 e perceberam que os CEOs mais narcisistas se preocupam mais com a responsabilidade social corporativa.

Com base na revisão de literatura apresentada, elencam-se as seguintes hipóteses de pesquisa.

- H2: Quanto mais forte o traço de personalidade maquiavélico, menor a responsabilidade social corporativa.

\subsection{Maquiavelismo e Gerenciamento de Resultados}

Hartmann e Maas (2010) desenvolveram um experimento com 136 contadores gerenciais e verificaram que o traço de personalidade maquiavélico propicia o gerenciamento de ganhos, dado que esses indivíduos são mais propensos a ceder à pressão da administração para criar folga orçamentária quando estão envolvidos na tomada de decisões. Shafer e Wang (2011) observaram que contadores chineses ricos em traços maquiavélicos são mais tolerantes às práticas de gerenciamento de resultados.

Murphy (2012) verificou que indivíduos dotados de Maquiavelismo são mais propensos a apresentar relatórios incorretos. Byington e Johnson (2011) perceberam a tendência dos indivíduos maquiavélicos para a manipulação de rubricas orçamentárias. Vladu (2013) evidenciou que indivíduos dotados de traços maquiavélicos consideram o gerenciamento de resultados uma prática aceitável.

D’Souza (2016) em estudo com 263 gestores verificou uma predisposição para manipulação de resultados daqueles ricos em Maquiavelismo e dos outros traços que compõem o cluster Dark Triad, Narcisismo e Psicopatia. Nessa mesma linha, D’Souza et al. (2019) perceberam que os três traços moderados do Dark Triad podem revelar comportamentos desejáveis no ambiente empresarial, mesmo quando estimulados a manipular resultados para maximização de ganhos. 
Diante da revisão de literatura apresentada, elenca-se a seguinte hipótese de pesquisa:

- H3: Quanto mais forte o traço de personalidade maquiavélico, maior a propensão para o gerenciamento de resultados.

Por fim, elabora-se a quarta hipótese de pesquisa no intuito de testar se a RSC modera a força do traço de personalidade sombrio na relação com o gerenciamento de resultados, haja vista a concepção de Shafer (2015) e Chih et al. (2008) que defendem que a RSC pode reduzir a motivação para o gerenciamento de resultados.

- H4: Quanto mais forte o traço de personalidade do maquiavelismo, maior a propensão ao gerenciamento de resultados, e esse relacionamento diminui na presença da responsabilidade social corporativa.

O estudo de Góis (2017) aplicou a moderação para verificar a força da relação entre os traços de personalidade sombrios - Dark Tetrad -, na relação com gerenciamento e fraude. O autor moderou a variável reputação corporativa pelo pressuposto de que valores, estruturas e regras formais ou informais construídas em empresas com forte reputação, poderiam reduzir o envolvimento de CEOs com traços altos de personalidades sombrias com gerenciamento de resultados e fraude. Os resultados apontaram que apenas os CEOs altamente maquiavélicos diminuíram o acometimento de fraude devido à forte reputação.

De forma semelhante, Silva (2019) moderou a variável governança corporativa para verificar a relação entre os traços do Dark Tetrad e o gerenciamento de resultados. No tocante ao gerenciamento por decisões reais, a interferência do nível elevado de narcisismo diminuiu a eficiência do conselho de administração, demonstrando influência para o aumento deste tipo de gerenciamento. Os traços elevados de psicopatia e sadismo, ao moderar o comitê de auditoria, diminuíram sua eficiência, impactando no aumento do gerenciamento de resultados por accruals.

\section{Metodologia}

\subsection{Abordagem, Técnica de Coleta de Dados e Amostra da Pesquisa}

Adotou-se a abordagem teórico-empírica, sendo o survey utilizado como estratégia de coleta de dados, por meio de um questionário autorrelato, composto de cinco partes: I - Termo de Consentimento Livre e Esclarecido (TCLE); II - perfil sociodemográfico; III - responsabilidade social corporativa, sendo cinco questões relativas à dimensão responsabilidade Econômica orientada aos proprietários (REP), seis à dimensão Responsabilidade Legal (RL) e seis à dimensão Responsabilidade Ética (RE), adaptadas do estudo de Shafer (2015), Maignan et al. (1999) e Leal (2013), que validou e ampliou o instrumento; IV - quatro cenários de Gerenciamento de Resultados (GR) ilustrados por meio de casos que remetem à manipulação contábil e operacional, adaptados dos estudos de Shafer (2015) e Merchant (1999); e V - 9 assertivas específicas que mensuram o traço do Maquiavelismo oriundas do instrumento Short Dark Triad (SD3) (Jones \& Paulhus, 2014), validado nacionalmente por D’Souza (2016).

A amostra da pesquisa envolveu profissionais de negócios que assumem ou já assumiram cargos de gestão em organizações e que participaram da International Conference in Accounting, no ano de 2018. O convite para participação foi enviado por e-mail, no mês de outubro do corrente ano, a 550 participantes que se inseriram no perfil requerido pela pesquisa e que disponibilizaram contatos válidos. Obteve-se o retorno de 208 participantes, dos quais $54 \%$ foram do sexo masculino, com maior predominância de faixa etária entre 26 a 35 anos (48,1\%), sendo maioria aqueles que possuem de 1 a 5 anos $(54,8 \%)$ de experiência na área de gestão. 
A escolha da amostra foi por acessibilidade e de forma não probabilística, o que não permite a generalização dos resultados, mas observação do fenômeno que remete ao objeto do estudo. O questionário mostrou-se confiável com uma Alpha de Cronbach de 0,765.

\subsection{Variáveis da Pesquisa, Parametrização e Abordagem Estatística}

De acordo com o objeto de estudo, o traço maquiavélico é a variável independente por explicar a responsabilidade social corporativa e o gerenciamento de resultados, consideradas neste estudo como variáveis dependentes para a testagem das hipóteses H1, H2 e H3. O desenho da pesquisa está ilustrado, conforme Figura 1:

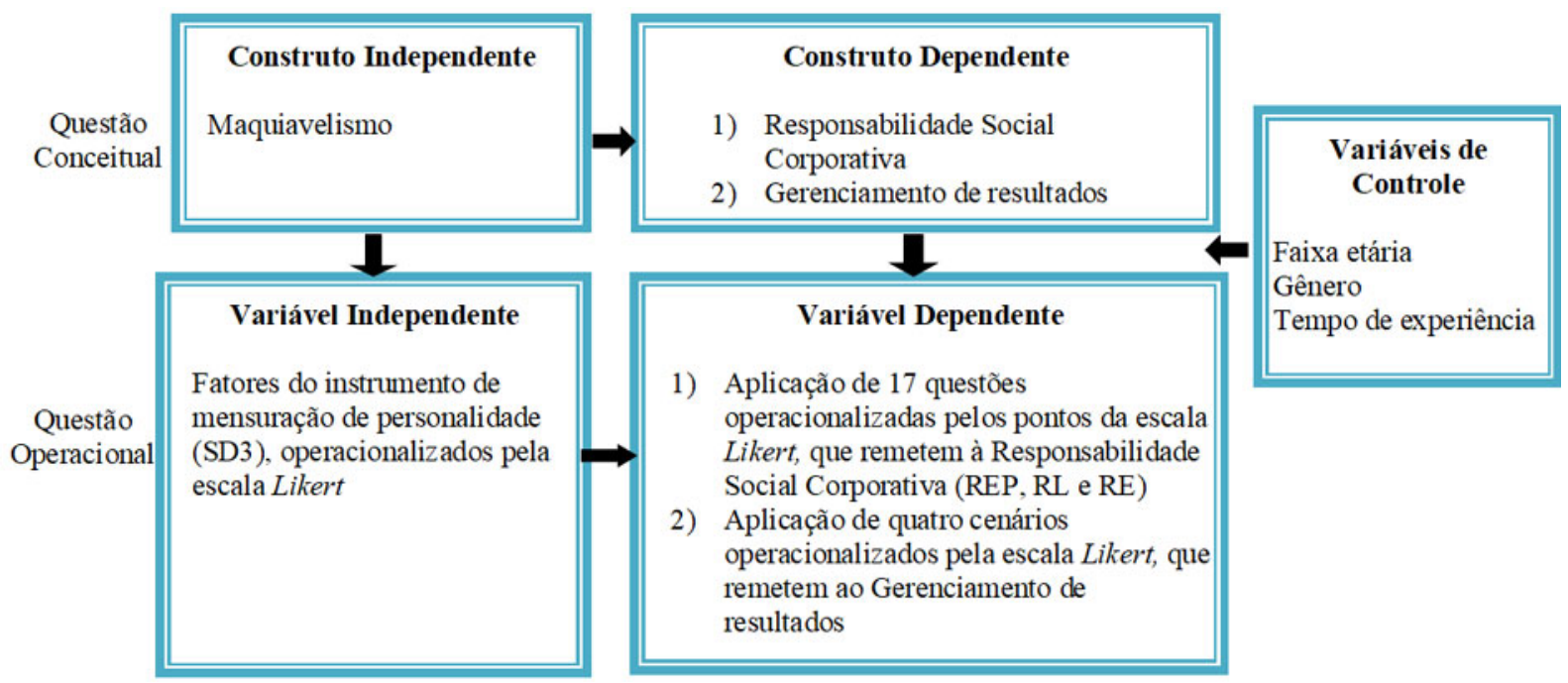

Figura 1. Desenho da pesquisa.

Para a testagem da hipótese $\mathrm{H} 4$, a variável responsabilidade social corporativa é considerada moderadora da relação entre o Maquiavelismo e o gerenciamento de resultados. Segundo Baron e Kenny (1986), uma variável moderadora afeta a direção (-/+) e/ou a força da relação entre variável independente e variável dependente. Nesse particular, procedeu-se a interação entre as variáveis (Maquiavelismo* REP), (Maquiavelismo*RE) e (Maquiavelismo*RL).

Em se tratando da operacionalização das variáveis da pesquisa, o instrumento (SD3) Jones e Paulhus (2014) foi aplicado para a mensuração do traço de personalidade do Maquiavelismo. São sete assertivas do tipo autorrelato, operacionalizadas pela escala Likert (1 a 7 pontos), tais como: "A maioria das pessoas pode ser manipulada"; "Não importa o que aconteça, você deve ter as pessoas importantes do seu lado"; "É prudente ter registro das informações que você poderá usar contra as pessoas mais tarde". Para mensuração, calculou-se a média de cada indivíduo e a do grupo. 
Para a variável responsabilidade corporativa, operacionalizada pela escala Likert (1 a 7 pontos), calculou-se a média das assertivas que remetem a cada uma das três dimensões das responsabilidades: REP, $\mathrm{RL}$ e RE. Cabe ressaltar que essas dimensões foram selecionadas por estarem mais bem relacionadas com o objeto do estudo, sobretudo, pela interface com os cenários do gerenciamento de resultados e com as características do traço maquiavélico, por exemplo: a dimensão econômica buscou conhecer a concordância para: "A empresa procura aumentar continuamente os seus lucros"; "A empresa preocupa-se em ser cada vez mais rentável". A dimensão legal buscou conhecer a concordância para: "A empresa atua prontamente de acordo com os regulamentos legais"; "Na empresa todos os nossos produtos e serviços cumprem as normas legais". E, por fim, a dimensão ética buscou conhecer a concordância para: "Em geral, a empresa cumpre os padrões e as normas éticas e profissionais"; "A empresa preocupa-se em fazer o que é eticamente correto".

Para a variável gerenciamento de resultados, foi calculada a média dos quatro cenários aplicados, operacionalizados pela escala Likert (1 a 7 pontos).

No que se refere à abordagem estatística, foi adotada a estatística descritiva (frequências, médias e desvio-padrão, valor máximo e mínimo) para se conhecer o perfil dos respondentes, a média aceitação para as práticas de gerenciamento de resultados e de responsabilidade social e a média para os traços maquiavélicos.

O teste de hipóteses foi utilizado para verificar se o perfil dos profissionais de negócios influencia na personalidade e nas escolhas, tal como enuncia a teoria do Alto Escalão. Para tanto, foram selecionados os testes Mann-Whitney e Kruskal-Wallis, devido à natureza das variáveis em estudo: qualitativas (Gênero: 0-feminino;1-masculino; Faixa etária: 1: de 18 a 25 anos; 2: de 26 a 35 anos; 3: de 36 a 45 anos e 4: Acima de 46 anos e Tempo de experiência: 1: de 1 a 5 anos; 2: de 6 a 10 anos; 3: de 11 a 15 anos; 4: de 16 a 20 anos; 5 de 21 a 25 anos, e 6: acima de 26 anos) e das variáveis quantitativas (média de GR; REP; RL e RE).

A correlação e regressão foram técnicas adotadas para analisar a relação, o sinal e a força entre as variáveis: gerenciamento de resultados, responsabilidade social corporativa e o Maquiavelismo. Para se conhecer a significância estatística das variáveis que demonstram maior relevância ao modelo e eliminar possíveis efeitos de multicolinearidade (Fávero, Befiore, Silva, \& Chan, 2009), adotou-se o método stepwise para o teste de regressão. Anterior à análise dos resultados oriundos da regressão, aplicou-se o teste de homocedasticidade, de autocorrelação dos resíduos e a linearidade dos parâmetros para verificar necessidade de ajustes. Com base no teorema do limite central, os dados tendem à normalidade.

\section{Resultados e Discussão}

Os resultados estão apresentados pelos modelos estatísticos para os testes das hipóteses elaboradas. Inicialmente, são apresentados os resultados descritivos e os testes de hipóteses com as variáveis de controle e as variáveis independente e dependente. Em seguida, o Modelo I discute a RSC e o GR; o Modelo II, o Maquiavelismo e a RSC, o Modelo III, o Maquiavelismo e o GR; e o Modelo IV, a RSC moderando a relação entre o Maquiavelismo e o GR.

Em relação à estatística descritiva, observa-se pela Tabela 4, que a maior média entre as três dimensões da $\operatorname{RSC}$ foi a $\operatorname{RE}(\bar{x}=6,7059)$, seguida da $\operatorname{RL}(\bar{x}=6,6867)$ e da $\operatorname{REP}(\bar{x}=6,1365)$. Esse resultado mostra altas concordâncias com as práticas da RSC, permitindo a inferência de que os respondentes respeitam aos requisitos legais e as condutas éticas na produção de bens e serviços que a sociedade necessita com enfoque no lucro. Esses resultados estão um pouco acima aos obtidos por Leal (2013), RL $(\bar{x}=6,0)$, $\operatorname{REP}(\bar{x}=5,81)$ e RE $(\bar{x}=5,59)$, no entanto, implicam reflexo positivo na operacionalização empresarial e nos relatórios contábeis. 
Ao analisar a aceitação para as práticas de GR, como a aceitação para os cenários de gerenciamento operacional $(\bar{x}=4,34)$ e gerenciamento contábil $(\bar{x}=2,73)$ observou-se maior concordância com as práticas de manipulação operacional. Esse achado, embora não muito expressivo, remete à concordância dos respondentes sobre a modificação de ganhos por meio da antecipação do registro de vendas, não registro de despesas no ano corrente e aumento de provisões. Resultado similar foi encontrado pelos estudos de Bruns e Merchant (1990) e Merchant e Rockness (1994). Para o presente estudo, foi adotada a média de aceitação $(\bar{x}=3,5361)$ dos dois cenários para toda a análise, dado que o objetivo do estudo é conhecer a disposição de gerenciar resultados de forma geral, metodologia em conformidade ao estudo de Shafer (2015).

No que se refere à orientação maquiavélica, a média de $(\bar{x}=3,7404)$ leva a uma concordância sobre as atitudes do traço sombrio, resultado que aponta uma propensão dos respondentes para uso de estratégia, tática, orientação para longo prazo e manipulação. Este achado é proporcionalmente inferior ao encontrado por Silva (2019), ( $\bar{x}=2,55814)$, e D'Souza (2016), $(\bar{x}=2,9155)$, quando as autoras pesquisaram gestores brasileiros, utilizando a escala de (1 a 5) pontos na escala Likert. Góis (2017) também verificou a média para o Maquiavelismo de $(\bar{x}=4,42)$ para estudantes de MBA brasileiros e $(\bar{x}=4,6)$ para norteamericanos, em uma escala de (1 a 10).

Tabela 3

\section{Estatística descritiva}

\begin{tabular}{lccccc}
\hline \multicolumn{1}{c}{ Variáveis } & $\begin{array}{c}\text { N. }{ }^{\circ} \text { de } \\
\text { Participantes }\end{array}$ & Mínimo & Máximo & Média & $\begin{array}{c}\text { Desvio- } \\
\text { padrão }\end{array}$ \\
\hline Responsabilidade Econômica & 208 & 2,20 & 7,00 & 6,1365 &, 86041 \\
\hline Responsabilidade Legal & 208 & 4,00 & 7,00 & 6,6867 &, 56727 \\
\hline Responsabilidade Ética & 208 & 4,00 & 7,00 & 6,7059 &, 48508 \\
\hline Gerenciamento de Resultados & 208 & 1,00 & 7,00 & 3,5361 & 1,29236 \\
\hline Maquiavelismo & 208 & 1,00 & 7,00 & 3,7404 & 1,14334 \\
\hline Fonte: dados da pesquisa. & & & & &
\end{tabular}

Em se tratando das variáveis de controle, o gênero se diferenciou na presença da RSC. Os homens demonstraram maior REP $(\bar{x}=6,2754)$, enquanto as mulheres apresentaram maiores disposições para a RE $(\bar{x}=6,7606)$ e a RL $(\bar{x}=6,7872)$. Aqui se verifica que as mulheres são mais dispostas a cumprirem a missão econômica dos negócios seguindo os requisitos legais, com base em uma conduta ética.

A faixa etária e o tempo de experiência se diferenciaram na presença do maquiavelismo. Os respondentes entre 18 e 25 anos apresentaram maior $(\bar{x}=3,9142)$ disposição para os traços maquiavélicos. Esse resultado se assemelha ao estudo de D'Souza e Lima (2018), que encontraram entre os estudantes de 17 e 25 anos $(\bar{x}=3,643364)$ maior predisposição para a manipulação e a estratégia. No que se refere ao tempo de experiência, aqueles que têm entre (1 e 5) anos de atividade laboral apresentaram maior orientação maquiavélica $(\bar{x}=3,9288)$. Isso significa que quanto menor o tempo de experiência, mais disposto a utilizar a estratégia para manipulação. 
Tabela 4

Testes de hipóteses

\begin{tabular}{llcllll}
\hline \multirow{2}{*}{ Variáveis } & \multirow{2}{*}{ Teste } & Maquiavelismo & GR & REP & RL & RE \\
\cline { 3 - 8 } & & Sig & Sig & Sig & Sig & Sig \\
\hline Gênero & Mann-Whiney &, 257 &, 268 &, $047\left(^{*}\right)$ &, $045\left(^{*}\right)$ &, $007\left(^{*}\right)$ \\
\hline Faixa etária & Kruskal-Wallis &, $000\left(^{*}\right)$ &, 076 &, 239 &, 410 &, 580 \\
\hline Tempo Experiência & Kruskal-Wallis &, $009\left(^{*}\right)$ &, 403 &, 137 &, 579 &, 964 \\
\hline
\end{tabular}

Nota: TempExper: Tempo de Experiência; GR: Gerenciamento de Resultados; REP: Responsabilidade Econômica; RL: Responsabilidade Legal; RE: Responsabilidade Ética.

$\left.{ }^{*}\right) p<, 05$.

Fonte: dados da pesquisa.

Esses resultados fundamentam-se na teoria do Alto Escalão (Hambrick, 2007), haja vista que características como idade, ocupação na empresa, experiência funcional, educação, raízes socioeconômicas e posição financeira possibilitam uma visão psicológica do comportamento humano. Logo, o retrato das características dos CEOs é determinante na escolha das estratégias e reflete nas escolhas de estratégias organizacionais.

\subsection{Modelo I - Responsabilidade Social Corporativa e Gerenciamento de Resultados}

Os resultados apontaram uma correlação significativa e positiva entre o RE e as REP e RL. Quando se analisa a relação da RSC com o GR, observa-se uma correlação significativa e negativa com a RL. Esse resultado permite a validação da hipótese $\mathrm{H} 1$ para a dimensão RL, pois, quanto maior a RL, menor a inclinação para o gerenciamento de resultados.

Permite também a inferência de que os respondentes se preocupam em obedecer a leis e regulamentos; portanto, a utilização do GR para a melhoria do desempenho da empresa não é um ato aceitável, seja violando ou não a informação contábil. No entanto, contrariamente às expectativas, a RE e a REP não se relacionaram com o GR. Ao confrontar resultados anteriores, Chih et al. (2008) verificaram com que quanto maior o compromisso das empresas com a responsabilidade social corporativa, menor a disposição para o gerenciamento de resultados. Já o estudo de Shafer (2015), com gestores italianos, evidenciou a racionalização do GR, na presença da RSC.

Tabela 5

Correlação RSC e GR

\begin{tabular}{lcccc}
\hline \multicolumn{1}{c}{ Variáveis } & REP & RL & RE & GR \\
\hline Responsabilidade Econômica & 1 & & & \\
\hline Responsabilidade Legal &, 067 & 1 & & \\
\hline Responsabilidade Ética &, $175\left(^{*}\right)$ &, $573\left(^{* *}\right)$ & 1 & 1 \\
\hline Gerenciamento de Resultados &, 127 &,- 200 (**) $^{*}$ &,- 083 & 1 \\
\hline
\end{tabular}

Nota: REP: Responsabilidade Econômica; RL: Responsabilidade Legal; RE: Responsabilidade Ética; GR: Gerenciamento de Resultados.

$\left({ }^{*}\right) p<, 01 ;(*) p<, 05$

Fonte: dados da pesquisa. 
Com o intuito de se verificar a significância do modelo, aplicou-se a regressão múltipla incluindo a variável dependente GR, as dimensões que remetem à RSC e as variáveis de controle (Tempo de Experiência, Idade e Gênero). Observa-se pela Tabela 6 que o modelo é significativo e que a REP foi significativa e positiva, enquanto a RL foi significativa e negativa.

Tabela 6

Regressão RSC e GR

\begin{tabular}{|c|c|c|c|c|c|c|c|}
\hline VD & \multicolumn{2}{|c|}{ Determinantes } & Variáveis & Coeficientes & $\begin{array}{c}\text { Erro } \\
\text { padrão }\end{array}$ & Estatística t & Sig \\
\hline \multirow{4}{*}{ GR } & R2 & ,078 & (Constante) & 5,479 & 1,167 & 4,694 & ,000 \\
\hline & R2 ajustado & ,064 & $\mathrm{RL}$ &,- 459 &, 154 & -2.982 & ,003 \\
\hline & Estatística F & 5,731 & REP & ,223 & , 101 & 2,198 & ,029 \\
\hline & P-valor (F) & 001 & TempExper & -125 & ,063 & $-1,990$ & ,048 \\
\hline
\end{tabular}

Nota 1: Teste Durbin-Watson=1,769; Teste White: $(p$-valor $=P(Q u i-q u a d r a d o(9)>11,1909)=0,26285 ; R L$ : Teste Tolerância 0,992; VIF: 1,008; REP: Teste Tolerância 0,993; VIF: 1,007; TempExper: Teste Tolerância 0,993; VIF: 1,007. Nota 2: VD: Variável Dependente; TempExper: Tempo de Experiência; REP: Responsabilidade Econômica; RL: Responsabilidade Legal; RE: Responsabilidade Ética; GR: Gerenciamento de Resultados.

Fonte: dados da pesquisa.

Aqui se destaca a significância positiva da REP que, também contrariando as expectativas, não inibe a prática de gerenciamento de resultados. Esse resultado chama a atenção de investidores para analisar melhor empresas que se posicionam como socialmente responsáveis e que praticam atos oportunistas para aumento do lucro e da rentabilidade. Beneficiam os acionistas e prejudicam os demais interessados na informação contábil. Os resultados também demonstram que quanto menor o tempo de experiência, maior a disposição para o gerenciamento de resultados. Profissionais mais jovens são mais dispostos a praticar o gerenciamento. Aqui também se observa os preceitos da teoria do Alto Escalão sobre o perfil do indivíduo, tal como o tempo de experiência, influenciar as decisões.

\subsection{Modelo II - Maquiavelismo e Responsabilidade Social Corporativa}

No que se refere à análise entre o Maquiavelismo e a RSC, observa-se pela Tabela 7 uma correlação negativa e significativa entre o Maquiavelismo e a RL e a RE. Pode-se inferir que a disposição para características maquiavélicas não motiva os participantes à obediência de leis e regulamentos e ao respeito às normas e aos valores da sociedade.

Tabela 7

Correlação Maquiavelismo e RSC

\begin{tabular}{lcccc}
\hline \multicolumn{1}{c}{ Variáveis } & REP & RL & RE & Maquiavelismo \\
\hline Responsabilidade Econômica & 1 & & & \\
\hline Responsabilidade Legal &, 067 & 1 & & \\
\hline Responsabilidade Ética &, $175\left(^{*}\right)$ &, $573(* *)$ & 1 & 1 \\
\hline Maquiavelismo &, 022 &,$- 257\left(^{* *}\right)$ &,$- 227\left(^{* *}\right)$ & \\
\hline
\end{tabular}

Nota: REP: Responsabilidade Econômica; RL: Responsabilidade Legal; RE: Responsabilidade Ética.

${ }^{(*)} p<, 01 ;(*) p<, 05$.

Fonte: dados da pesquisa. 
Quando as variáveis de controle e as três dimensões da RSC como variáveis dependentes foram inseridas, de forma individualizada, observou-se a não significância para o maquiavelismo e REP. Este achado se contradiz ao de Burton e Hegarty (1999), que evidenciaram que estudantes de negócios ricos em Maquiavelismo demonstraram REP. Por outro lado, como previsto, o Maquiavelismo explica, de forma significativa e negativa, a RL e RE no presente estudo.

Tabela 8

Regressão RL e RE e as variáveis do Modelo II

\begin{tabular}{|c|c|c|c|c|c|c|c|}
\hline \multirow[t]{2}{*}{$\begin{array}{c}\text { Variável } \\
\text { dependente }\end{array}$} & \multicolumn{2}{|c|}{ Determinantes } & \multirow[t]{2}{*}{ Variáveis } & \multirow[t]{2}{*}{ Coeficientes } & \multirow[t]{2}{*}{$\begin{array}{c}\text { Erro } \\
\text { padrão }\end{array}$} & \multirow[t]{2}{*}{$\begin{array}{c}\text { Estatística } \\
\mathrm{t}\end{array}$} & \multirow[t]{2}{*}{ Sig } \\
\hline & $\mathrm{R}^{2}$ & ,059 & & & & & \\
\hline \multirow[t]{4}{*}{${ }^{*} \mathrm{RL}$} & $\mathrm{R}^{2}$ ajustado & ,055 & (Constante) & 7,105 & ,0954 & 74,51 & ,000 \\
\hline & Estatística F & 13,109 & Maquiavelismo &,- 111 &, 0306 & $-3,621$ & ,000 \\
\hline & P-valor (F) & ,000 & & & & & \\
\hline & $\mathrm{R}^{2}$ & ,076 & & & & & \\
\hline \multirow[t]{3}{*}{$*_{\mathrm{RE}}$} & $\mathrm{R}^{2}$ ajustado & ,067 & (Constante) & 7,119 & ,093 & 75,80 & ,000 \\
\hline & Estatística F & 8,470 & Maquiavelismo &,- 090 & ,028 & $-3,280$ & ,001 \\
\hline & P-valor (F) & ,000 & Gênero &,- 126 & ,028 & $-2,308$ & ,022 \\
\hline
\end{tabular}

Nota 1: *Heterocedasticidade corrigida: estatísticas baseadas em dados ponderados.

Nota 2: REP: Responsabilidade Econômica; RL: Responsabilidade Legal; RE: Responsabilidade Ética; TempExper: Tempo de Experiência.

Fonte: dados da pesquisa.

Observa-se pela Tabela 8 que à medida que aumenta a força do traço maquiavélico, a responsabilidade social diminui. Esse resultado está em consonância com o de Burton e Hegarty (1999), que observaram a diminuição da RE e RL com o aumento dos traços maquiavélicos, e com o de Shafer (2018), que também encontrou forte associação negativa entre o Maquiavelismo e a responsabilidade social corporativa.

Ainda é possível observar que a variável gênero se apresentou significativa e negativa na presença da responsabilidade ética. Aqui se observam os preceitos da teoria do Alto Escalão sobre o perfil do indivíduo, tal como o gênero, influenciar as escolhas e os valores. Esses resultados permitem validar parcialmente a hipótese $\mathrm{H} 2$.

\subsection{Modelo III - Maquiavelismo e Gerenciamento de Resultados}

A Tabela 9 apresenta a correlação positiva e significativa entre o Maquiavelismo e o GR. Podese inferir que a ausência de princípios, estratégia e os baixos padrões de ética e moral dos indivíduos maquiavélicos motivam a utilização de manobras contábeis e operacionais, tais como: adiamento de despesas discricionárias, aumento de provisões, postergação de despesas do exercício e antecipação de vendas para melhoria do desempenho empresarial. 
Tabela 9

Correlação Maquiavelismo e Gerenciamento de Resultados

\begin{tabular}{lcc}
\hline \multicolumn{1}{c}{ Variáveis } & GR & Maquiavelismo \\
\hline GR & 1 & \\
\hline Maquiavelismo &, $294(* *)$ & 1 \\
\hline
\end{tabular}

Nota 1: GR: Gerenciamento Resultados.

Fonte: dados da pesquisa.

Ao inserir as variáveis de controle, adotando o GR como variável dependente, observa-se um modelo significativo e a confirmação de que o Maquiavelismo explica o GR de forma significativa e positiva. Quanto mais fortes os traços de Maquiavelismo, maior a disposição dos respondentes para atitudes que implicam gerenciar operacionalmente e/ou contabilmente os ganhos. De uma forma ou de outra, haverá a distorção das informações contábil e gerencial, que beneficiará de forma oportunista o acionista ou a empresa responsável pela informação.

Tabela 10

Regressão Maquiavelismo e GR

\begin{tabular}{c|l|c|ccccc}
\hline \multirow{2}{*}{ VD } & \multicolumn{2}{|c|}{ Determinantes } & Variáveis & Coeficientes & $\begin{array}{c}\text { Erro } \\
\text { padrão }\end{array}$ & Estatística t & Sig \\
\hline \multirow{4}{*}{ GR } & R2 &, 078 & & & & & \\
\cline { 2 - 8 } & R2 ajustado &, 064 & (Constante) & 2,292 &, 294 & 7,788 &, 000 \\
\cline { 2 - 8 } & Estatística F & 5,731 & Maquiavelismo &, 333 & 4,075 & 418 &, 000 \\
\cline { 2 - 8 } & P-valor (F) &, 001 & & & & & \\
\hline
\end{tabular}

Nota 1: Teste Durbin-Watson=1,835; Teste de Breusch-Pagan( $p$-valor $=P(Q u i-q u a d r a d o(1)>0,301209)=0,579398$. Teste Tolerância 0,999; VIF: 1.

Nota 2: VD: Variável dependente; GR: Gerenciamento de Resultados.

Fonte: dados da pesquisa.

Esse resultado está em consonância com os achados de D'Souza et al. (2019), Silva (2019), Góis (2017), Vladu (2013), Murphy (2012), Shafer e Wang (2011), Byington e Johnson (2011) e Hartmann e Maas (2010) e chama a atenção da comunidade, sobretudo contábil, para os possíveis prejuízos causados por gestores com traços de personalidade sombrios nas empresas. Esse resultado permite validar a hipótese $\mathrm{H} 3$.

\subsection{Modelo IV - Responsabilidade Social Corporativa Moderando a Relação entre o Maquiavelismo e o Gerenciamento de resultados}

Com o desígnio de analisar o efeito moderador da variável RSC na relação entre o Maquiavelismo e o GR, aplicou-se a interação entre as variáveis, $\left(M a q u i^{\star} R E P\right),\left(M a q u i^{\star} R L\right),\left(M a q u{ }^{\star} R E\right)$. Observou-se uma associação significativa e positiva das variáveis moderadoras com o GR $(r=, 333, p=, 000),(r=, 277, p=, 000)$, $(\mathrm{r}=, 231, \mathrm{p}=, 000)$, destacando a Maqui ${ }^{\star} R E P$ com maior associação, seguida da Maqui ${ }^{*} R E$. Posteriormente, aplicou-se regressão múltipla, conforme a tabela 11. 
Tabela 11

Regressão (Maqui*REP), (Maqui*RL), (Maqui*RE)e o GR

\begin{tabular}{|c|c|c|c|c|c|c|c|}
\hline \multirow[t]{2}{*}{ VD } & \multicolumn{2}{|c|}{ Determinantes } & \multirow[t]{2}{*}{ Variáveis } & \multirow[t]{2}{*}{ Coeficientes } & \multirow[t]{2}{*}{ Erro padrão } & \multirow[t]{2}{*}{ Estatística t } & \multirow[t]{2}{*}{ Sig } \\
\hline & $\mathrm{R}^{2}$ & ,111 & & & & & \\
\hline & $\mathrm{R}^{2}$ ajustado & , 107 & (Constante) & 2,305 & ,257 & 8,958 &, 000 \\
\hline & Estatística F & 25,675 & Maqui*REP & ,054 & 011 & 5,067 &, 000 \\
\hline & P-valor (F) & ,000 & & & & & \\
\hline & $\mathrm{R}^{2}$ &, 054 & & & & & \\
\hline \multirow[t]{7}{*}{ GR } & $\mathrm{R}^{2}$ ajustado & .049 & (Constante) & 2,538 & ,305 & 8,318 & ,000 \\
\hline & Estatística F & 11,648 & Maqui*RL & ,040 & ,012 & 3,413 & ,001 \\
\hline & P-valor (F) & ,001 & & & & & \\
\hline & $\mathrm{R}^{2}$ & ,076 & & & & & \\
\hline & $\mathrm{R}^{2}$ ajustado & ,072 & (Constante) & 2,355 & ,299 & 7,884 & ,000 \\
\hline & Estatística F & 17,060 & Maqui*RE & ,047 & ,011 & 4,130 &, 000 \\
\hline & P-valor (F) & ,000 & & & & & \\
\hline
\end{tabular}

Nota 1: Maqui*RE: Teste Durbin-Watson=1,830; Teste Breusch-Pagan:(p-valor=P(Qui-quadrado(1)>

0,514631)=0,473141; Teste Tolerância:1; VIF: 1.Maqui*RL: Teste Durbin-Watson=1,862; Teste Breusch-Pagan:(p-

valor $=P(Q u i-q u a d r a d o(1)>0,316236)=0,573878 ;$ Teste Tolerância: 1; VIF: 1.Maqui*RE: Teste Durbin-Watson=1,866; Teste

Breusch-Pagan:(p-valor=P(Qui-quadrado(1)> 0,720008)=0,396141;Teste Tolerância:1; VIF: 1.

Nota 2: VD: Variável Dependente; GR: Gerenciamento de Resultados.

$(* *) p<, 01 ;(*) p<, 05$.

Fonte: dados da pesquisa.

Os resultados indicam, contrariamente às expectativas, que a moderação da RSC é significativa e positiva para as três dimensões, indicando que a RSC causa influência sobre a relação entre o Maquiavelismo e o GR. Outro aspecto importante a ser destacado é o de que a moderação da RSC não teve força para inibir, mas aumentou a relação entre o Maquiavelismo e o gerenciamento.

Portanto, os achados revelam que, mesmo na presença da RSC, quanto mais fortes os traços maquiavélicos, maiores serão as atitudes de modificar ganhos para gerar benefícios ao gestor ou para a empresa, ainda que para isso as normas legais, éticas e profissionais sejam quebradas. Isto realça a análise da estratégia maquiavélica em buscar e apresentar melhores resultados da empresa para atração de investimentos, crédito, mesmo que para tanto sejam apresentados resultados que não retratam a verdadeira situação da empresa. Esse achado tem implicações econômicas e financeiras e serve como referência para investidores que utilizam os resultados relatados nas demonstrações contábeis para investir nas empresas. Para auditores observarem com maior zelo as informações contábeis relatadas para emitirem opiniões independentes e livres de risco sobre empresas que usam a RSC como pano de fundo para gerenciar resultados.

Esse resultado não valida a hipótese H4 e diverge dos achados de Góis (2017), que constatou que a reputação corporativa modera e inibe a relação entre o Maquiavelismo e fraude. E Silva (2019), que também verificou que a moderação da governança corporativa resultou em uma relação negativa entre Maquiavelismo e o GR.

Em suma, os resultados do estudo fundamentam-se na teoria do Alto Escalão e permitem a inferência de que a responsabilidade legal reduz a força do gerenciamento de resultados, o que valida parcialmente a hipótese $\mathrm{H} 1$. O traço maquiavélico reduz a disposição para a responsabilidade legal e ética, o que valida parcialmente a hipótese H2. Quanto mais forte o traço maquiavélico, mais forte a relação com o GR, o que valida a hipótese H3. Por fim, a moderação da RSC não foi capaz de inibir a relação positiva entre o traço sombrio e o gerenciamento de resultados, o que não valida a hipótese $\mathrm{H} 4$. 


\section{Conclusão}

O estudo com 208 profissionais de negócios revelou que aqueles que se preocupam em observar as políticas que remetem à responsabilidade legal, não concordam com a prática de gerenciamento de resultados, no entanto, aqueles que focalizam a responsabilidade econômica, apresentaram disposição para o gerenciamento. Isso significa que quando os profissionais se deparam com a possibilidade de melhorar o desempenho empresarial e pessoal, para aumentar o lucro continuamente, práticas que violam ou não as práticas contábeis são aceitas, sem a preocupação com o impacto ou o prejuízo causado para a sociedade pelo uso do gerenciamento de resultados.

Sobre a influência maquiavélica, aqueles mais dotados desses traços apresentaram menor disposição para a responsabilidade corporativa legal e ética e aceitação para o gerenciamento de resultados. Inferese então que a orientação estratégica e os baixos padrões de ética e moral do indivíduo maquiavélico influenciam na prática do gerenciamento de resultados, especialmente porque a insensibilidade que lhe é característica reduz a análise das consequências futuras, o que pode impactar o reporte incorreto da informação contábil, a imagem empresarial e o futuro dos funcionários e investidores. Se por um lado os indivíduos maquiavélicos poderiam utilizar a RSC como ferramenta de projeção para melhorar a sua reputação e a da empresa perante a sociedade, por outro lado as fortes características oportunista e manipuladora se sobressaem.

O resultado sobre a influência maquiavélica no gerenciamento de resultados não surpreende, haja vista o caráter sombrio do traço que motiva comportamentos desonestos, notadamente pela insensibilidade e cinismo. No entanto, esse achado chama a atenção para as empresas observarem e acompanharem profissionais dotados desses traços, para não persuadirem a equipe de trabalho para o acometimento de atos oportunistas que podem comprometer em longo prazo a continuidade da empresa.

Quando se aplicou a moderação da RSC para verificar uma possível inibição da relação entre o maquiavelismo e o gerenciamento de resultados, observou-se que as três dimensões da RSC mostraram influência, porém, com efeito positivo; logo, a moderação não reduziu a relação positiva entre as variáveis do estudo. Nesse particular, esse resultado surpreendeu, mas ao mesmo tempo pode ser entendido, haja vista a responsabilidade econômica ter se associado positivamente ao gerenciamento de resultados, e o gerenciamento ter se associado também positivamente ao Maquiavelismo. Portanto, o caráter sombrio do traço se sobressai à disposição da RSC, sobretudo quanto à REP que demonstrou maior poder explicativo entre as três dimensões. Essa responsabilidade visa ao lucro e à rentabilidade, ativos desejados por aqueles que gerenciam resultados, desconsiderando práticas que violam ou não a lei.

Cabe aqui ainda pontuar que os profissionais do sexo masculino apresentaram maior responsabilidade econômica, demonstrando maior foco no lucro, redução de custos e rentabilidade empresarial, enquanto as mulheres foram mais sensíveis aos princípios de responsabilidade ética e legal. Em adição, os profissionais entre 18 a 25 anos tiveram maiores disposições maquiavélicas, o que permite a inferência de que quanto mais jovens, maior a orientação para o futuro e menor preocupação com os possíveis atos desonestos. Aqueles com menor experiência parecem ser mais maquiavélicos, resultado que se alinha com o anterior.

Esses resultados se fundamentam na teoria do Alto Escalão, haja vista que as características dos indivíduos, tais como perfil, valores e personalidade, promovem interpretações, escolhas, atitudes e comportamentos.

Nesse contexto, a presente pesquisa alcançou o objetivo proposto por apresentar os resultados empíricos que fornecem informações relevantes para gestores, acionistas, reguladores, responsáveis pela governança corporativa sobre a influência de traços de personalidade do Maquiavelismo como motivador ao acometimento de gerenciamento de resultados e menor aderência à RSC. 
Esses resultados limitam-se a uma análise comportamental, sem a pretensão diagnóstica e clínica dos profissionais de negócios envolvidos no estudo, tampouco a generalização dos achados. Sugerese, como pesquisas futuras, ampliar a amostra analisada, bem como incluir variáveis moderadoras que possam ter potencialidade para inibir a relação de traços de personalidade sombrios e o gerenciamento de resultados, para se conhecer os resultados diferenciados do fenômeno em estudo.

\section{Referências}

Abernathy, J. L., Beyer, B., \& Rapley, E. T. (2014). Earnings management constraints and classification shifting.Journal of Business Finance \& Accounting, 41(5-6), 600-626. Doi: 10.1111/jbfa.12076

Aguinis, H. (2011). Organizational responsibility: Doing good and doing well. In S. Zedeck (Ed.), APA handbook of industrial and organizational psychology 3, 855-879. Washington, DC: American Psychological Association. Doi: 10.1037/12171-024

Baron, R. M., \& Kenny, D. A. (1986). The moderator-mediator variable distinction in social psychological research: Conceptual, strategic, and statistical considerations. Journal of personality and social psychology, 51(6), 1173. Doi: 10.1037//0022-3514.51.6.1173

Bruns, W. J., \& Merchant, K. A. (1990). The dangerous morality of managing earnings. Management Accounting, 72,22-25. Recuperado em https://www.hbs.edu/faculty/Pages/item.aspx?num=2605

Burton, B. K., \& Hegarty, W. H. (1999). Some determinants of student corporate social responsibility orientation. Business \& society, 38(2),188-205. Doi: https://doi.org/10.1177/000765039903800204

Byington, J. R., \& Johnson, G. H. (2011). Machiavellianism and accounting competence: effects on budgetary attitudes.Journal of Applied Business Research (JABR),6(3), 98-104. Doi: 10.19030/jabr. v6i3.6295

Callan, S. J., \& Thomas, J. M. (2009). Corporate financial performance and corporate social performance: An update investigation. Corporate Social Responsibility and Reinvestigation, 16, 61-78. Doi: https:// doi.org/10.1002/csr.182

Carroll, A. B. (1979). A three-dimensional conceptual model of corporate performance. The Academy of Management Review, 4(4), 497-505. Doi: https://doi.org/10.2307/257850

Chih, H. L., Shen, C. H., \& Kang, F. C. (2008). Corporate social responsibility, investor protection, and earnings management: Some international evidence. Journal of business ethics, 79(1-2), 179-198. Doi: 10.1007/s10551-007-9383-7

Christie, R., \& Geis, F. L. (1970). Studies in machiavellianism. New York: Academic Press.

D’Souza, M. F. (2016). Manobras financeiras e o Dark Triad: o despertar do lado sombrio na gestão. Tese de Doutorado, Universidade de São Paulo, São Paulo, SP, Brasil.

D'Souza, M. F., \& Lima, G. A. S. F. (2015). The dark side of power: the dark triad in opportunistic decisionmaking. Journal Advances in Scientific and Applied Accounting, 8(2), 135-156. Doi: 10.14392/ asaa.2015080201

D’Souza, M. F., Lima, G. A. S. F. D., Jones, D. N., \& Carre, J. R. (2019). Eu ganho, a empresa ganha ou ganhamos juntos?: traços moderados do darktriad e a maximização de lucros. Revista de Contabilidade \& Finanças, 30(79),123-138.Doi: https://doi.org/10.1590/1808-057x201806020

Drucker, P. F. (1984). The new meaning of corporate social responsibility. California Management Review, 26,53-63. Recuperado em https://cmr.berkeley.edu/search/articleDetail.aspx?article $=5402$ 
Fávero, L. P. L., Belfiore, P. P., Silva, F. L., \& Chan, B. L. (2009). Análise de dados: modelagem multivariada para tomada de decisões. Rio de Janeiro: Campus Elsevier.

Góis, A. D. (2017). The dark tetrad of personality and the accounting information quality: The moderating effect of corporate reputation. Tese de Doutorado, Faculdade de Economia, Administração e Contabilidade, Universidade de São Paulo. Doi: 10.11606/T.12.2018.tde-22022018-171814

Hambrick, D. C. (2007). Upper echelons theory: an update. Academy of Management Review, 32(2), 334343. Doi: https://doi.org/10.2307/20159303

Hambrick, D. C., \& Mason, P. A. (1984). Upper echelons: the organization as a reflection of its top managers. Academy of Management Review, 9(2), 193-206. Doi: https://doi.org/10.2307/258434

Hartmann, F. G. H., \& Maas, V. S. (2010, January). Why business unit controllers create budget slack: involvement in management, social pressure, and machiavellianism. Behavioral Research in Accounting,22(2), 27-49. Doi: 10.2308/bria.2010.22.2.27

Healy, P. M. (1985). The effect of bonus schemes on accounting decisions. Journal of Accounting and Economics, 7(1), 85-107. Doi: https://doi.org/10.1016/0165-4101(85)90029-1

Hong, Y., \& Andersen, M. (2011). Corporate social responsibility, investor protection, and earnings management: Some international evidence. Journal of Business Ethics, 79, 179-198. Recuperado de: https://www.jstor.org/stable/41476320

Jones, D. N. (2016). The nature of Machiavellianism: Distinct patterns of misbehavior. In V. Zeigleer-Hill \& D. K. Marcus (Eds.). The dark side of personality: Science and practice in social, personality, and clinical psychology. Washington, DC: American Psychological Association.

Jones, D. N., \&Paulhus D. L. (2009). Machiavellianism. In M. R., Levy, \& R. H., Hoyle. (Eds.),Individual differences in social behavior (93-108). New York: Guilford.

Jones, D. N., \&Paulhus, D. L. (2011). Differentiating the dark triad within the interpersonal circumplex. In L. M., Horowitz, \& S., Strack. Handbook of interpersonal psychology (249-269). New York: Wiley and Sons.

Jones, D. N., \&Paulhus, D. L. (2014). Introducing the short dark triad (SD3): a brief measure of dark personality traits. Assessment, 21(1), 28-41.Doi: https://doi.org/10.1177/1073191113514105

Leal, S.C.H. (2013). As percepções de responsabilidade social das empresas e o capital psicológico como antecedentes do empenhamento e do desempenho (Tese de Doutorado em Gestão de Empresas). Universidade de Coimbra, Portugal.

Lin, H., Sui, Y., Ma, H., Wang, L., \&Zeng, S. (2018). CEO narcissism, public concern, and megaproject social responsibility: Moderated mediating examination. Journal of Management in Engineering, 34(4), 04018018. Doi: 10.1061/(ASCE)ME.1943-5479.000062

Maignan, I., Ferrell, O. C. \&Hult, G. T. M. (1999). Corporate citizenship: Cultural antecedents and business benefits. Journal of the Academy of Marketing Science, 27(4), 455-469. Doi: $10.1177 / 0092070399274005$

McVay, S. E. (2006). Earnings management using classification shifting: an examination of core earnings and special items. The Accounting Review, 81(3), 501-531.Recuperadoem: https://www.jstor.org/ stable/4093104

Merchant, K. A. (1989). Rewarding results: Motivating profit Center managers. Boston, MA: Harvard Business School Press.

Merchant, K. A., \&Rockness, J. (1994). The ethics of managing earnings: An empirical investigation. Journal of Accounting and Public Policy, 13,79-94. Doi: https://doi.org/10.1016/0278-4254(94)90013-2 
Mohanram, P. S. (2003). How to manage earnings management. Accounting World, 10, 13-19. Recuperado em: https://www.researchgate.net/publication/251563109_HOW_TO_MANAGE_EARNINGS_ MANAGEMENT1

Murphy, P. R. (2012). Attitude, machiavellianism and the rationalization of misreporting. Accounting, Organizations and Society,37(4),242-259. Doi: 10.1016/j.aos.2012.04.002

Orlitzky, M., Schmidt, F. L. \&Rynes, S. L. (2003). Corporate social and financial performance: A metaanalysis. Organization Studies, 24(3),403-411. Doi: 10.1177/0170840603024003910

Petrenko, O. V., Aime, F., Ridge, J., \& Hill, A. (2016). Corporate social responsibility or CEO narcissism? CSR motivations and organizational performance. Strategic Management Journal, 37(2),262-279. Doi: http://hdl.handle.net/10.1002/smj.2348

Shafer, W. E., \&Lucianetti, L. (2018). Machiavellianism, stakeholder orientation, and support for sustainability reporting. Business Ethics: A European Review, 27(3), 272-285. Doi: 10.1111/beer.12187

Shafer, W. E., \& Wang, Z. (2011). Effects of ethical context and Machiavellianism on attitudes toward earnings management in China. Managerial Auditing Journal, 26(5), 372-392. Doi: $10.1108 / 02686901111129553$

Shafer, W. E. (2015). Ethical climate, social responsibility, and earnings management. Journal of Business Ethics, 126(1),43-60.Doi: 10.1007/s10551-013-1989-3

Silva, Alini da. (2019). Influência do Dark Tetrad de Executivos na Relação entre os Mecanismos de Governança Corporativa e a Prática de Gerenciamento de Resultados. Tese. Doutorado em Ciências Contábeis e Administração - Programa de Pós-Graduação em Ciências Contábeis da Universidade Regional de Blumenau, Blumenau, $260 \mathrm{f}$.

Tang, Y., Mack, D. Z., \& Chen, G. (2018). The differential effects of CEO narcissism and hubris on corporate social responsibility. Strategic Management Journal,39(5), 1370-1387. Doi: 10.1002/smj.2761

Vladu, A. B. (2013). Machiavellianism and short-term earnings management practices. Annales Universitatis - Apulensis Series Oeconomica, 15(2),467-472. Doi: 10.29302/oeconomica.2013.15.2.12 